\title{
Hypopituitarism after treatment of haemophagocytic syndrome associated with Epstein-Barr virus -positive aggressive natural killer cell leukemia
}

\author{
Xue Liang ${ }^{1}$, Han Wang ${ }^{2}$, Xiao Mao ${ }^{1}$, Zhiqiong Wang ${ }^{1}$, Wei Huang*1 \\ ${ }^{1}$ Department of Hematology, Tongji Hospital, Tongji Medical College, Hua Zhong University of Science and Technology, China \\ ${ }^{2}$ Department of Hematology, Hubei TCM hospital, Wu Han, Hubei, China.
}

${ }^{*}$ Correspondence to: Wei Huang, Department of Hematology, Tongji Hospital, Tongji Medical College, Hua Zhong University of Science and Technology, No.1095, Jiefang avenue, Wuhan, China - 430030; Tel: 027-83663611; E-mail: 2896607051@qq.com

Received: April 03, 2018; Accepted: April 24, 2018; Published: April 26, 2018;

\begin{abstract}
INTRODUCTION: Haemophagocytic syndrome is a life-threatening clinical syndrome, which can lead to tissue damage and progressive systemic organ failure. But there was no report on hypopituitarism induced by haemophagocytic syndrome.

PURPOSE: Here we reported one case of hypopituitarism after treatment of haemophagocytic syndrome associated with Epstein-Barr virus -positive aggressive natural killer cell leukemia. After haemophagocytic syndrome control, the patient felt too weak, tired and dizzy to sit up, he also had symptom of depression, loss of appetite, polyuria and hypotension. Lab tests found Low hormone levels, including thyroid stimulating hormone, free tri-iodothyronine, free thyroxine, testosterone. adrenocorticotropic hormone stimulation test showed was abnormal. So, the patient was diagnosed as hypopituitarism.

DISCUSSION: HLH is a life-threatening clinical syndrome, and the illness is so serious that physicians focus all their attention on disease treatment, ignoring the hypopituitarism. We reviewed pathologic mechanisms of haemophagocytic syndrome associated with Epstein-Barr virus -positive aggressive natural killer cell leukemia inducing hypopituitarism. The cytokine storm might play an important role in pathologic process of hypopituitarism induced by haemophagocytic syndrome. This is first report on hypopituitarism after treatment of haemophagocytic syndrome associated with Epstein-Barr virus -positive aggressive natural killer cell leukemia.
\end{abstract}

Key words: hypopituitarism, haemophagocytic syndrome, cytokine storm

\section{Introduction}

Hypopituitarism is defined as insufficiency of one or more pituitary hormones owing to a lesion in the hypothalamic-pituitary region. This disease is an uncommon disease with a prevalence of $\sim 46$ per 100 000 [1]. The pituitary gland has two lobes. Six hormones are produced within the anterior lobe: growth hormone, adrenocorticotropic hormone (ACTH), the gonadotropins follicle stimulating hormone (FSH), luteinising hormone, thyroid stimulating hormone (TSH), and prolactin. The posterior pituitary lobe contains two hormones, oxytocin and antidiuretic hormone (ADH).

The most common cause of hypopituitarism was related to a sellar mass, which is nonfunctioning pituitary macroadenoma. Hypopituitarism might occur because of pituitary surgery and/or pituitary radiotherapy. Other less prevalent causes of hypopituitarism included radiation and traumatic brain injury. Rarely, vascular diseases also could induce hypopituitarism, such as pituitary apoplexy, Sheehan's syndrome, subarachnoid hemorrhage and aneurysm. More rarely, inflammatory processes such as lymphocytic hypophysitis have been associated with hypopituitarism.
Haemophagocyticsyndrome(hemophagocyticlymphohistiocytosis, $\mathrm{HLH}$ ) is a life-threatening clinical syndrome that is characterized by fever, organomegaly, and pancytopenia [2]. Primary HLH may result from genetic defects. Secondary HLH may be acquired with infectious, neoplastic, autoinflammatory, autoimmune, and immunodeficiency etiologies. Here we reported one case of secondary HLH associated with Epstein-Barr virus (EBV)-positive aggressive natural killer cell leukemia(ANKL), the patient developed into hypopituitarism, after secondary HLH associated with EBV-positive ANKL was controlled. This is the first report on hypopituitarism induced by HLH, and we reviewed the cytokine storm might be responsible for pathologic mechanisms of HLH inducing hypopituitarism.

\section{Case Report}

A previously healthy 24-year-old man was brought to the hepatology department in our hospital with recurrent fever, yellow sclera for 6 days since July 22, 2017. His social history was negative for high-risk sexual behavior, ethanol and drug abuse. His family history was noncontributory. Physical examination revealed temperature of $39.5^{\circ} \mathrm{C}$, nodal tachycardia with normal blood pressure and breaths, 
splenomegaly without superficial lymph node enlargement. The laboratory data revealed abnormal liver function studies with aspartate aminotransferase(AST) 181.3 units/L (normal: < 40 units/L), alanine aminotransferase (ALT) 233.8 units/L (normal: < 41 units/L), total bilirubin 135.3umol/L(3.4-20 umol/L), normal alkaline phosphatase. The laboratory data also revealed leukopenia $\left[1.95 \times 10^{9} / \mathrm{L}\right.$ (normal: $3.5-9.5 \times 10^{9} / \mathrm{L}$ ) $]$, neutrophil deficiency $[0.48 \times 109 / \mathrm{L}$ (normal: $1.8-6.3 \times 109 / \mathrm{L}$ )], thrombocytopenia [ $97 \times 10^{9} / \mathrm{L}$ (normal: $100-300$ $\times 10^{9} / \mathrm{L}$ )] with normal level of haemoglobin and normal coagulation function. Erythrocyte sedimentation rate was normal and C-reactive protein levels were increasing $[46.9 \mathrm{mg} / \mathrm{L}<$ normal: $<10)]$. The level of interleukin 6 increased to $93 \mathrm{pg} / \mathrm{ml}$ (normal: $<7$ ). Doppler ultrasound of his abdomen showed moderate splenomegaly. Computed tomography of his chest showed normality. After admission, she was empirically started on meropenem and vancomycin for febrile neutropenia and treatment of liver protection. Fever was not controlled, and the patient developed into pancytopenia. In August 1, the laboratory data revealed leukopenia $\left(1.74 \times 10^{9} / \mathrm{L}\right)$, thrombocytopenia $\left(29 \times 10^{9} / \mathrm{L}\right)$, decreased level of haemoglobin(HB) [90g/L (normal: 120-160)] and decreased level of fibrinogen [1.1g/L (normal: 2-4)]. His ferritin level was greater than 50,000 ug/L < normal: 30-400), and interleukin 6 level was more than $597 \mathrm{pg} / \mathrm{ml}$. Blood cultures were negative. An initial autoimmune workup revealed normality. Viral workup, by IgM antibody and viral titers, was negative for human immunodeficiency virus, hepatitis $\mathrm{A}, \mathrm{B}$, and $\mathrm{C}$, herpes simplex virus, herpes zoster, parvovirus, cytomegalovirus, hantavirus, puumala virus, and adenovirus. Epstein-Barr virus (EBV)-DNA copy number is increasing, EBVDNA in peripheral blood mononuclear cell (PBMC) is $2.77 \times 10^{5} / \mathrm{L}$ (normal: 500/L), EBV-DNA in blood plasma is $8.46 \times 10^{3} / \mathrm{L}$ (normal: 500/L). The patient was diagnosed HLH and was transferred to hematology department. Than he received bone marrow puncture, bone marrow aspiration revealed there were $6 \%$ prolymphocyte like cells. Flow cytometric analysis of bone marrow revealed that $7.4 \%$ nucleated cells were abnormal immunophenotyp natural killer (NK) cells (CD45bri+, CD56bri+, Ki67+, CD16-, CD57-, cCD3-, CD158b-, CD158ah-, TCRrd-, TCRab-) (Figure 1). Perforin and CD107a tests showed normality. Finally, he was diagnosed aggressive ANKL [3] and secondary HLH according to HLH diagnostic criteria [5], then he immediately received the treatment according to according to HLH-2004 treatment protocol [4] in August 2, but this patient did not receive treatment of ciclosporin because of abnormality of liver function. This patient received treatment of plasmapheresis and ruxolitinib(Jakafi) (5mg bid). After 13 days of treatment the patient had no fever, his total bilirubin dropped to $58 \mathrm{umol} / \mathrm{L}$ and level of fibrinogen restored to normality. But the patient felt too weak, tired and dizzy to sit up. Symptoms also included depression and loss of appetite. His blood pressure is as low as $80 / 40 \mathrm{mmHg}$, and he peed more than $4000 \mathrm{ml}$ a day. These do not arouse the attention of physicians. Symptoms was simply explained as disease itself, the low blood pressure was simply explained as postural hypotension, the cause of urorrhagia was simply explained as no fever. Then the patient received chemotherapy of GemOx protocol (Gemcitabine $1000 \mathrm{mg} / \mathrm{m}^{2} \mathrm{~d} 1 \mathrm{~d} 15$, oxaliplatin $\left.100 \mathrm{mg} / \mathrm{m}^{2} \mathrm{~d} 1 \mathrm{~d} 15\right)$. After 30 days of treatment his ferritin level dropped to $2762 \mathrm{ug} / \mathrm{L}$, both of EBV-DNA copy number in PBMC and blood plasma were negative. The level of interleukin 6 decreased to $56 \mathrm{pg} / \mathrm{ml}$ (normal: $<7$ ). Flow cytometry did not detect aggressive NK cell. His symptoms are not improving, so he was suspected of having hypopituitarism and pituitary hormone levels were tested. Hypopituitarism was confirmed on a subsequent testing of pituitary hormone levels (Table 1). ACTH stimulation test showed was abnormal, with a sub optimal response to $0.25 \mathrm{mg}$ ACTH with a level of $245 \mathrm{ug} / \mathrm{L}$ after $30 \mathrm{~min}$ and $366 \mathrm{ug} / \mathrm{L}$ after $60 \mathrm{~min}$ (a low baseline cortisol concentration of $24.01 \mathrm{ug} / \mathrm{L}$ ). A pituitary magnetic resonance imaging (MRI) enhancement scanning was then performed, there was no manifestation of tumor infiltration. The patient received euthyrox, midodrine and prednisone.
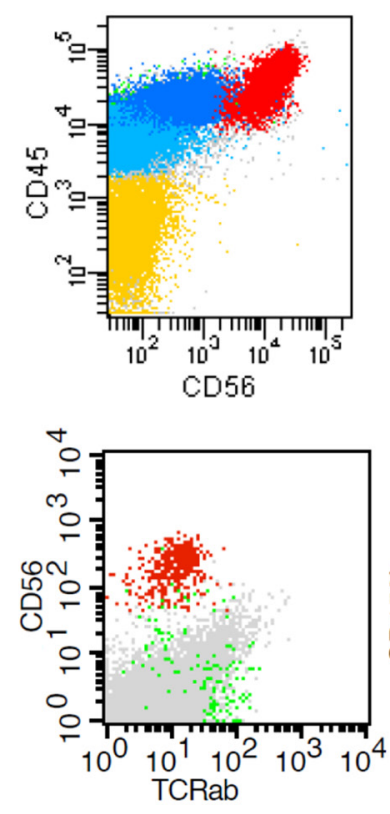
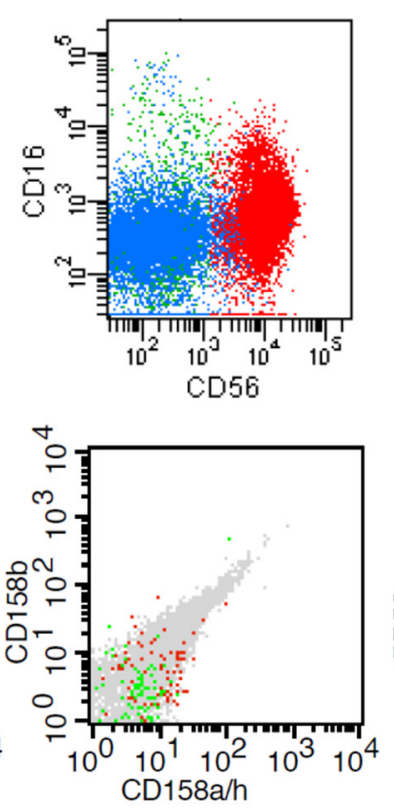
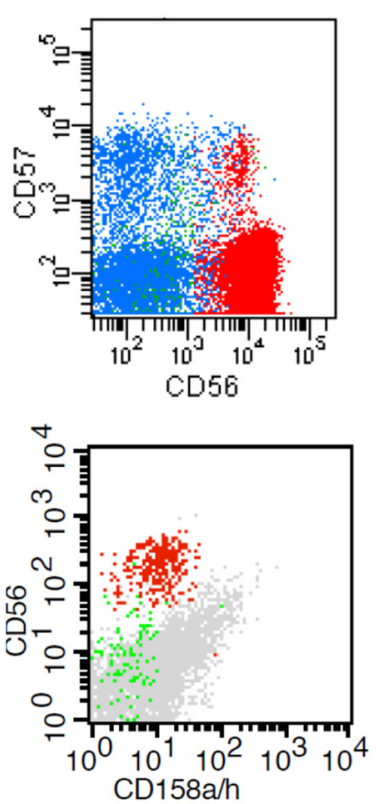
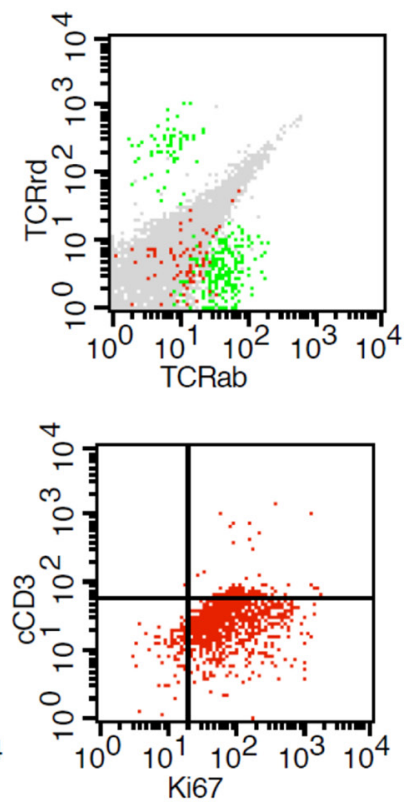

Figure 1. Phenotypic abnormalities of NK cells detected by a multicolor flow cytometric 
Wei Huang (2018) Hypopituitarism after treatment of haemophagocytic syndrome associated with Epstein-Barr virus -positive aggressive natural killer cell leukemia

Table 1. Pituitary and other hormone levels

\begin{tabular}{|l|c|c|c|}
\hline \multicolumn{1}{|c|}{ Serum } & Level & Range & Units \\
\hline thyroid stimulating hormone & 0.053 & $0.35-4.94$ & $\mathrm{uIU} / \mathrm{ml}$ \\
\hline free tri-iodothyronine & 1.32 & $1.71-3.71$ & $\mathrm{pg} / \mathrm{ml}$ \\
\hline free thyroxine & 0.62 & $0.7-1.48$ & $\mathrm{ng} / \mathrm{dl}$ \\
\hline testosterone & 0.36 & $1.75-7.8$ & $\mathrm{ng} / \mathrm{ml}$ \\
\hline prolactin & 12.05 & $2.64-13.13$ & $\mathrm{ng} / \mathrm{ml}$ \\
\hline adrenocorticotrophic hormone & 1.93 & $1.6-13.9$ & $\mathrm{pmol} / \mathrm{L}$ \\
\hline cortisol & 21.92 & $60.2-184$ & $\mathrm{ug} / \mathrm{L}$ \\
\hline
\end{tabular}

\section{Discussion}

There was no report on hypopituitarism caused by HLH, there was no report on hypopituitarism caused by EBV, and there was no report on hypopituitarism caused by ANKL. The patient was healthy before he was sick. HLH associated with EBV-positive ANKL was inferred causing hypopituitarism. How to understand hypopituitarism after treatment of HLH associated with EBV-positive ANKL? From the pathophysiological process of HLH we can explain why he had hypopituitarism.

Haemophagocytic syndrome is a life-threatening disease with immune regulatory disorder. The underlying common mechanism is a defect in granule mediated cytotoxicity, which is important in killing cells [6]. The perforin plays an important role in the homoeostasis of dendritic cells and restrict T-cell activation by antigen presentation [7]. Perforin and CD107a tests are more sensitive and no less specific compared with NK cytotoxicity testing for screening for genetic HLH, and perforin and CD107a tests should be considered for addition to current genetic HLH criteria [8]. This patient had normal level of perforin and CD107a, which suggested that he was secondary HLH, not primary HLH. The uncontrolled activation of dendritic cells and restrict T-cell produces an exaggerated inflammatory response, which is called cytokine storm. The cytokine storm is characterized by hypersecretion of proinflammatory cytokines such as interferon $\gamma$, tumor necrosis factor a (TNF $\alpha)$, interleukin-1, interleukin-4, interleukin-6, interleukin-8, interleukin -10, and interleukin-18 [9]. This cytokine storm could pathogenically have a bearing on the development of the main clinical and laboratory features of HLH [10], leads to tissue damage and progressive systemic organ failure, which can be partly prevented by antibody of cytokines, such as interleukin 6 , interleukin $18[11,12]$. In this case, the high level of interleukin 6 showed the cytokine storm.

In rare cases, inflammatory processes have been associated with hypopituitarism, although the common cause of hypopituitarism is pituitary adenoma, treatment with pituitary surgery or radiotherapy cancer, trauma and vascular injury. Autoimmune hypophysitis $(\mathrm{AH})$ is a chronic inflammatory disease, which is characterized by infiltration of $\mathrm{T}$ and $\mathrm{B}$ lymphocytes in the pituitary gland. A growing number of reports of hypophysitis was accompanied by anti-cancer immunotherapy, such as programmed cell death protein 1 (PD-1) inhibitors and cytotoxic T-lymphocyte antigen 4 (CTLA-4) inhibitors [13]. In the mouse model of $\mathrm{AH}$ there was increased levels of interferon- $\gamma$ and interleukin-17, which may participate in pathogenic mechanism of $\mathrm{AH}$ [14]. There were reports about hypopituitarism during the treatment of hepatitis $\mathrm{C}$ virus infection with IFN-alpha $[15,16]$. So, we have reason to believe that cytokine storms may be involved in the pathologic process of hypophysitis.

Although there was no report on hypopituitarism caused by HLH, CNS involvement is a frequent finding at HLH onset [17]. In addition, either at presentation or during the course of HLH, CNS disease has been reported in $30-73 \%$ of all HLH [18]. This patient had no central symptom, hypopituitarism might be sign of CNS involvement of HLH.

Viral infections are also a rare cause of hypopituitarism. The current reports showed that the viruses causing hypopituitarism included human immunodeficiency virus (HIV) [19-22], hanta virus [23], puumala virus [24], newcastle disease virus [25]. Except CMV virus, other virus test is negative in this case. There was no report on EBV causing hypopituitarism. EBV infection played important role in ANKL and HLH, and ANKL was easy to develop into HLH. So, we thought the immediate cause of hypopituitarism was HLH.

In addition to pituitary adenomas, there were other tumors that could cause hypopituitarism, such as pituitary lymphoma [26, 27]. A pituitary magnetic resonance imaging (MRI) enhancement scanning excluded the pituitary tumor in this case.

In a word, this is first report on hypopituitarism after treatment of haemophagocytic syndrome associated with EBV-positive ANKL. The cytokine storm might play an important role in pathologic process of hypopituitarism.

\section{Competing interests}

No competing interests as defined by Molecular Medicine, or other interests that might be perceived to influence the results and discussion reported in this paper.

\section{Funding}

This work was supported by grants from the National Natural Science Foundation of China (No. 81770164).

\section{Acknowledgements}

We thank the patient and his family for their participation in this study.

\section{References}

1. Higham CE, Johannsson G, Shalet SM (2016) Hypopituitarism. Lancet 388: 24032415. [Crossref]

2. Jordan MB, Allen CE, Weitzman S et al (2011) How I treat hemophagocytic lymphohistiocytosis. Blood 118: 4041-4052. [Crossref]

3. Li Y, Wei J, Mao X et al (2016) Flow Cytometric Immunophenotyping Is Sensitive for the Early Diagnosis of De Novo Aggressive Natural Killer Cell Leukemia (ANKL): A Multicenter Retrospective Analysis. PLoS One 11: e0158827. [Crossref]

4. Henter JI, Horne A, Aricó M et al (2007) HLH-2004: diagnostic and theraputic guidelines for haemophagocytic lymphohistiocytosis. Pediatr Blood Cancer 48: $124-131$. [Crossref]

5. Ramos-Casals M, Brito-Zerón P, López-Guillermo A et al (2014) Adult haemophagocytic syndrome. Lancet 383: 1503-1516. [Crossref]

6. Arceci RJ (2008) When T cells and macrophages do not talk: the hemophagocytic syndromes. Curr Opin Hematol 15: 359-367. [Crossref]

7. Chen M, Felix K, Wang J (2012) Critical role for perforin- and Fas dependent killing of dendritic cells in the control of inflammation. Blood 119: 127-136. [Crossref] 
Wei Huang (2018) Hypopituitarism after treatment of haemophagocytic syndrome associated with Epstein-Barr virus -positive aggressive natural killer cell leukemia

8. Rubin TS, Zhang K, Gifford C et al (2017) Perforin and CD107a testing is superior to NK cell function testing for screening patients for genetic HLH. Blood 129: 2993-2999. [Crossref]

9. Sumegi J, Barnes MG, Nestheide SV et al (2011) Gene expression profi ling of peripheral blood mononuclear cells from children with active hemophagocytic lymphohistiocytosis. Blood 117: e151-160. [Crossref]

10. Canna SW, Behrens EM (2012) Not all hemophagocytes are created equally: appreciating the heterogeneity of the hemophagocytic syndromes. Curr Opin Rheumatol 24: 113-118. [Crossref]

11. Chen F, Teachey DT, Pequignot E et al (2016) Measuring IL-6 and sIL-6R in serum from patients treated with tocilizumab and/or siltuximab following CAR $\mathrm{T}$ cell therapy. J Immunol Methods 434: 1-8. [Crossref]

12. Chiossone L, Audonnet S, Chetaille B et al (2012) Protection from inflammatory organ damage in a murine model of hemophagocytic lymphohistiocytosis using treatment with IL-18 binding protein. Front Immunol 3: 239. [Crossref]

13. Sidhu P, Menzies AM, Long G et al (2017) Radiological manifestations of immune-related adverse effects observed in patients with melanoma undergoing immunotherapy. J Med Imaging Radiat Oncol 61: 759-766. [Crossref]

14. Lin HH, Gutenberg A, Chen TY et al (2017) In Situ Activation of PituitaryInfiltrating $\mathrm{T}$ Lymphocytes in Autoimmune Hypophysitis. Sci Rep 7: 43492. [Crossref]

15. Ridruejo E, Christensen AF, Mando OG (2006) Central hypothyroidism and hypophysitis during treatment of chronic hepatitis $\mathrm{C}$ with pegylated interferon alpha and ribavirin. Eur J Gastroenterol Hepatol 18: 693-694.[Crossref]

16. Concha LB, Carlson HE, Heimann A et al (2003) Interferon induced hypopituitarism. Am J Med 114: 161-163. [Crossref]

17. Deiva K, Mahlaoui N, Beaudonnet F et al (2012) CNS involvement at the onset of primary hemophagocytic lymphohistiocytosis. Neurology 78: 1150-1156. [Crossref]
18. Jovanovic A, Kuzmanovic M, Kravljanac R et al (2014) Central nervous system involvement in hemophagocytic lymphohistiocytosis: a single-center experience. Pediatr Neurol 50: 233-237. [Crossref]

19. Rochira V, Guaraldi G (2017) Growth hormone deficiency and human immunodeficiency virus. Best Pract Res Clin Endocrinol Metab 31: 91-111. [Crossref]

20. Diazzi C, Brigante G, Ferrannini G et al (2017) Pituitary growth hormone (GH) secretion is partially rescued in HIV-infected patients with GH deficiency (GHD) compared to hypopituitary patients. Endocrine 55: 885-898. [Crossref]

21. Kim J, Mooradian AD (2000) Hyperinsulinemic hypoglycemia associated with possible hypopituitarism in a patient with acquired immunodeficiency syndrome. Endocr Pract 6: 453-455. [Crossref]

22. Nduwayo L, Nsabiyumva F, Osorio Salazar C et al (1992) Endocrinological aspects of acquired immunodeficiency syndrome (AIDS). Med Trop (Mars). 52: 139-143.

23. Jost C, Krause R, Graninger W et al (2009) Transient hypopituitarism in a patient with nephropathia epidemica. BMJ Case Rep 2009: bcr02.2009.1538.

24. Forslund T, Saltevo J, Anttinen J et al (1992) Complications of nephropathia epidemica: three cases. J Intern Med 232: 87-90.[Crossref]

25. Blalock JE, Smith EM (1985) A complete regulatory loop between the immune and neuroendocrine systems. Fed Proc 44: 108-111. [Crossref]

26. Kozáková D, Macháleková K, Brtko P et al (2008) Primary B-cell pituitary lymphoma of the Burkitt type: case report of the rare clinic entity with typical clinical presentation. Cas Lek Cesk 147: 569-573. [Crossref]

27. Liu JK, Sayama C, Chin SS et al (2007) Extranodal NK/T-cell lymphoma presenting as a pituitary mass. Case report and review of the literature. Neurosurg. 107: 660-665.

\section{Citation:}

Xue Liang, Han Wang, Xiao Mao, Zhiqiong Wang, Wei Huang (2018) Hypopituitarism after treatment of haemophagocytic syndrome associated with Epstein-Barr virus -positive aggressive natural killer cell leukemia. Internal Med Res Open J Volume 3(3): 1-4 